\title{
Finnish National Phenological Network 1997-2017: from observations to trend detection
}

\author{
Samuli Helama ${ }^{1}$ (D) $\cdot$ Anne Tolvanen ${ }^{2} \cdot$ Jouni Karhu $^{2} \cdot$ Jarmo Poikolainen $^{2} \cdot$ Eero Kubin $^{2}$
}

Received: 18 November 2019 / Revised: 20 April 2020 / Accepted: 26 June 2020 / Published online: 6 July 2020

(C) The Author(s) 2020

\begin{abstract}
Plant phenological dataset collected at 42 sites across the mainland of Finland and covering the years 1997-2017 is presented and analysed for temporal trends. The dataset of $n=16,257$ observations represents eleven plant species and fifteen phenological stages and results in forty different variables, i.e. phenophases. Trend analysis was carried out for $n=808$ phenological timeseries that contained at least 10 observations over the 21-year study period. A clear signal of advancing spring and early-summer phenology was detected, 3.4 days decade ${ }^{-1}$, demonstrated by a high proportion of negative trends for phenophases occurring in April through June. Latitudinal correlation indicated stronger signal of spring and early-summer phenology towards the northern part of the study region. The autumn signal was less consistent and showed larger within-site variations than those observed in other seasons. More than $60 \%$ of the dates based on single tree/monitoring square were exactly the same as the averages from multiple trees/monitoring squares within the site. In particular, the reliability of data on autumn phenology was increased by multiple observations per site. The network is no longer active.
\end{abstract}

Keywords Plant phenology $\cdot$ Advance of spring $\cdot$ Autumn phenology $\cdot$ Boreal ecosystems $\cdot$ Climate research

\section{Introduction}

Phenology provides excellent opportunities for studying climatic changes and their impacts on ecosystems. The changes in the annual cycle of plants are closely linked to the seasonal course of temperature, light and water supply, among other factors, and phenological observations constitute direct evidence of plants' responses to these changes. With these regards, phenological data contribute tangibly to our understanding of global change biology (Menzel 2000, 2002; Parmesan and Yohe 2003; Piao et al. 2019; Menzel et al. 2020). In Europe, the plant phenological data have demonstrated an average advance of spring/summer 2.5 days per

Electronic supplementary material The online version of this article (https://doi.org/10.1007/s00484-020-01961-6) contains supplementary material, which is available to authorized users.

Samuli Helama

samuli.helama@luke.fi

1 Natural Resources Institute Finland, Ounasjoentie 6, 96200 Rovaniemi, Finland

2 Natural Resources Institute Finland, University of Oulu, P.O. Box 413, 90014 Oulu, Finland decade between the years 1971 and 2000, in accordance with instrumentally observed warming (Menzel et al. 2006). A more recent analysis of European phenological data (19712010) identified significant species-specific advancements in plant flowering onsets across the continent, with the highest magnitude of change 2.2 to 9.6 days per decade obtained for boreal conditions; moreover, more pronounced phenological changes were detected over the later decades, since 1991, in comparison with earlier years (Templ et al. 2017). While these trends demonstrate the value of phenological analyses in detecting the effects of recent and ongoing changes in growing season climate on ecosystems, they also indicate the instrumental role of high-latitude phenological observations, i.e. those from boreal and Arctic settings (Wielgolaski and Inouye 2013) in estimating the changes of presumably highest magnitude taking place over the most recent times.

Plant phenological data from boreal and subarctic settings are available from the Finnish National Phenological Network (FNPN), originally established by the Finnish Forest Research Institute in 1995 (Poikolainen et al. 1997; Kubin et al. 2006) to systematically follow the changes in forest ecological responses to climatic change (Kubin 1993). In Finland, plant phenological data have been continuously collected since 1750 s with involvement of several institutional organisations 
and scientific societies 1750s (Kubin et al. 2008; Terhivuo et al. 2009; Holopainen et al. 2012). The more recent parts of the subsets of these data have previously been analysed mainly for purposes of the climatic analysis (Lappalainen and Heikinheimo 1992; Häkkinen et al. 1995; Holopainen et al. 2006, 2013; Linkosalo et al. 2009). Within the FNPN, the phenology of forest trees and shrubs was monitored since the spring of 1997 via a nationwide observation network in collaboration with universities, state research institutions, and vocational schools and colleges using a unified protocol (Kubin et al. 2007a, b). This collection of the data continued in cooperation with activities through the COST action 725 (Nekovár et al. 2008) with an objective of unifying the protocols of observations. Another objective was to create a common database of phenological observations through the continent, an undertaking now constituting the Pan European Phenological database PEP725 with updates of FNPN data (Koch et al. 2008; Templ et al. 2018). As of Jan 1, 2015, the Finnish Forest Research Institute was integrated into the Natural Resources Institute Finland, and the phenological observations were continued under this institute until the autumn of 2017.

Various parts of the FNPN dataset have been previously analysed. Pudas et al. (2008a) investigated the timing of Betula pubescens phenophases at 30 sites across Finland during 1997-2006. Pudas et al. (2008b) focussed on phenophases of various plant species observed only in the northernmost part of the country (Lapland) over the same period. Overall, they connected the advancing onsets of spring phenophases with year-to-year changes in the mean May temperature but found no trends in autumn phenophases (Pudas et al. 2008a, b). Terhivuo et al. (2009) presented an analysis of long-term phenological trends concentrating on Prunus padus and Sorbus aucuparia time-series, to place their recent flowering dates in the context of historical phenological data. They showed that the flowering dates had changed by 3 and 2 days later, as observed for $P$. padus and S. aucuparia, in comparison with the historical baseline. Ranta et al. (2010) used the leafing time-series of Populus tremula from thirty stations across the country (1997-2007) to analyse the synchrony in leafing as a function of the sites' distances and temperature data in terms of the Moran effect to demonstrate that the phenological events can be synchronised the same way as population fluctuations. Poikolainen et al. (2016) analysed the trends in spring and autumn phenophases of B. pubescens observed at 21 sites (1997-2013) across the southern, middle, and northern boreal zones in Finland, in connection with annual temperature (in degree day units) cycle. During their study period, the bud burst had advanced 8 days and, in 2013, the average dates of 15,18 , and 26 May for southern, middle, and northern boreal sites were recorded. Moreover, the length of the growing period was, on average, 136, 122, and 130 days at the southern, middle, and northern boreal sites (Poikolainen et al. 2016).
Furthermore, the FNPN dataset is now part of the Pan European Phenological database PEP725 (Koch et al. 2008; Templ et al. 2018), the successor of the database developed through the COST action 725 (Nekováŕ et al. 2008), the PEP725 dataset currently consisting of more than ten million phenological time-series related to 121 wild plant and 144 cultivars from altogether ca. 20,000 different sites across Europe (Templ et al. 2018). Within this entity of data, Menzel et al. (2006) classified the FNPN data as among the national specialist networks. As a consequence, the FNPN data will be foreseeably investigated in a number of research projects and programs in the future. Recently, Templ et al. (2017) analysed the data of flowering dates of six plant species collected at 963 sites located between 40.9 and $67.9^{\circ} \mathrm{N}$ in twelve European countries (1970-2010), their analyses including the relevant parts of the FNPN dataset. Their results showed remarked advancements in plant flowering onsets, with a delay in this phenological stage with an increase in latitude, and an advance with changing climate (Templ et al. 2017).

The full FNPN dataset has not been hitherto described in the literature. The purpose of this study is to present these plant phenological observations from Finland covering the full period of data collection between the years 1997 and 2017. First, we itemise the dataset according to observed plant species, phenological stages, and phenophases (combining the species and its phenological stage). We also present the spatiotemporal coverage of the available observations. Second, the temporal trends in the phenological time-series (19972017) are assessed by their (slope) strengths, seasonal representativeness, and geographical variation. Third, a comparison is made where multiple within-site observations are available. Fourth, the results are discussed for the spring and autumn signals by highlighting their overall indications for climate research and characterising the FNPN data in the context of other relevant phenological data.

\section{Material and methods}

\section{Plant phenological data}

The dataset collected by the Finnish Forest Research Institute/ Natural Resources Institute Finland contains altogether 43,589 plant phenological observations made by the stuff of the research institute using a ratified protocol (Kubin et al. $2007 \mathrm{a}, \mathrm{b}$ ) at 42 sites (between $70^{\circ} \mathrm{N}$ and $60^{\circ} \mathrm{N}$, and $20^{\circ} \mathrm{E}$ and $30^{\circ}$ E) (Fig. 1a) on eleven plant species typical to Finnish forests around the country between the years 1997 and 2017. No observations were made on the Åland Islands (an archipelago between the mainlands of Finland and Sweden). Phenological stages were recorded predominantly from five individual trees per site since 2007, after which ten additional trees were recorded per site since 2010 for improved 


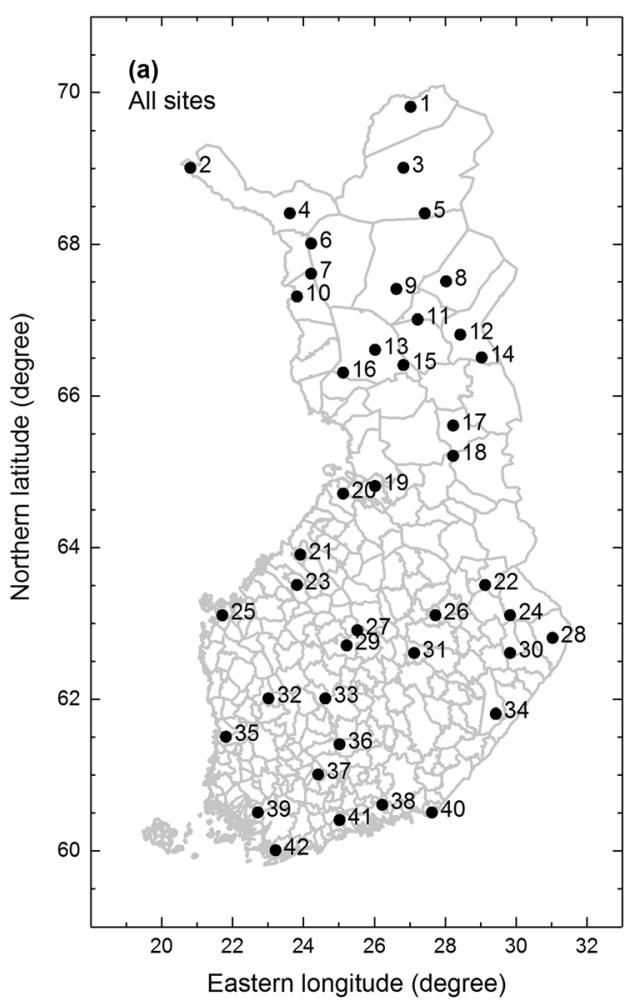

Fig. 1 Maps of Finland with phenological observation sites over the full period (1750-1875) (a), and over the years of 1998 (b) and 2017 (c). The sites are numbered as follows: (1) Kevo, (2) Kilpisjärvi, (3) Muddusjärvi, (4) Hetta, (5) Saariselkä, (6) Pallasjärvi, (7) Äkäslompolo, (8) Värriö, (9) Sodankylä, (10) Kolari, (11) Pyhätunturi, (12) Salmivaara, (13) Apukka, (14) Oulanka, (15) Kivalo, (16) Pisavaara, (17) Taivalkoski, (18)

representativeness of data. Medium-sized and healthy trees were included in these observations. The observations on shrubs were made within the monitoring squares $\left(1 \mathrm{~m}^{2}\right)$. Similar to change in observing the trees, their number was increased from one to five since 2007. These observations were made on fifteen phenophases: berries ripe, berries unripe, bud burst, bud scales opened, end of height growth, female flowering $100 \%$, flowering, leaf colouring, leaf fall, leaves full-sized, leaves opened, onset of female flowering, onset of height growth, onset of male flowering, and shedding of seeds, in association with the BBCH codes (Meier 2001). The observed species were aspen (Populus tremula L.), bilberry (Vaccinium myrtillus L.), bird-cherry (Prunus padus L.), cowberry (Vaccinium vitis-idaea L.), downy birch (Betula pubescens Ehrh.), grey alder (Alnus incana (L.) Moench), common juniper (Juniperus communis L.), Norway spruce (Picea abies (L.) Karsten), rowan (Sorbus aucuparia L.), Scots pine (Pinus sylvestris L.), and silver birch (Betula pendula Roth). The abundance of flowering, berry yields, and seed crops as well as the observations on the most common damages affecting the trees was also monitored within the observation network. These data are not inherently phenological and were not included in this paper. (c)

Sites in 2017

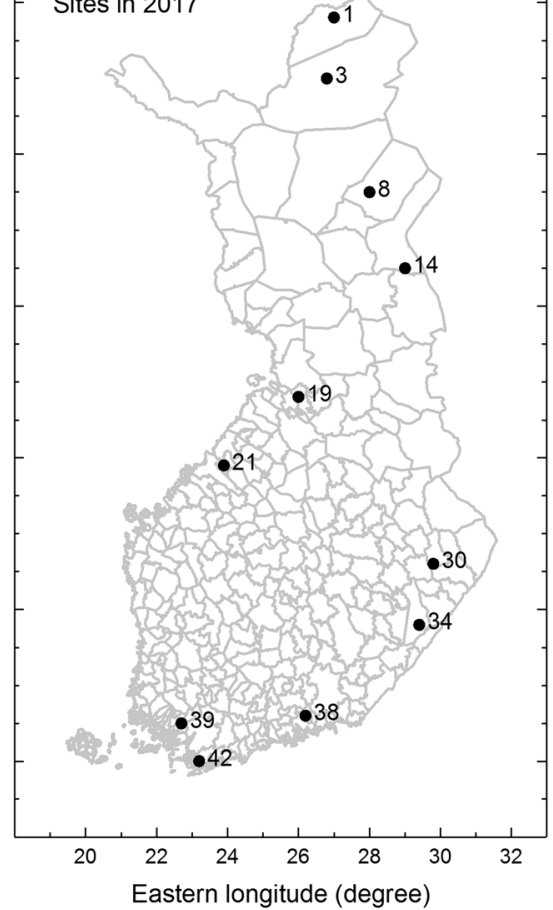

Paljakka, (19) Muhos, (20) Ruukki, (21) Kannus, (22) Nurmes, (23) Veteli, (24) Koli, (25) Korsholm, (26) Siilinjärvi, (27) Pyhähäkki, (28) Mekrijärvi, (29) Kolkanlahti, (30) Joensuu, (31) Suonenjoki, (32) Parkano, (33) Vilppula, (34) Punkaharju, (35) Pori, (36) Vesijako, (37) Aulanko, (38) Lapinjärvi, (39) Preitilä, (40) Ravijoki, (41) Ruotsinkylä, and (42) Solböle

In this paper, the FNPN dataset was characterised for the observations per site, for phenological records (series of observations representing the species, phenological stage, and site), and time-series (records containing at least 10 observations over the 21-year study period).

\section{The vernal equinox}

An important detail regarding the time-series of phenological observations relates to the mismatch between the length of the solar year and the slightly longer average year on the Gregorian calendar (Sagarin and Micheli 2001). The possibility of an overestimation of trends towards earlier spring signals, and the benefits of adopting the dates of phenological observations in relation to the beginning of astronomical spring (vernal equinox) rather than by calendar day, has been previously presented (Sagarin 2001, 2009). Here we follow these recommendations and report our phenological dates as the number of days elapsed since the vernal equinox, i.e. the date the sun crosses the celestial equator from the austral to the boreal hemisphere that have, over the years under this study, varied between 20 and 21 March. 


\section{Characterising the data}

The dataset was characterised by the distributions of the observations as a function of their seasonal, spatial, and temporal coverage, the number of species and phenological stages. Moreover, temporal trends in the phenological time-series were calculated using approaches commonly applied in analyses of time-series (e.g. Menzel 2000; Schaber and Badeck 2005; Terhivuo et al. 2009; Eastman et al. 2013; Hamunyela et al. 2013; Zhou et al. 2016; Williams et al. 2018). The MannKendall (MK) statistic (Kendall 1970; Mann 1945) was used to determine the statistical significance of the trends, and the rate of change (slope) was estimated using the Theil-Sen approach, also known as Sen's (1968) slope, with 95\% confidence interval for the estimate (Conover 1980). These estimations were made using the mean phenological time-series produced by averaging the $n=1-15$ observations available on same phenophase (combining the species and phenological stage) for each site. Slope estimates were also compared with the sites' latitudes and longitudes using the Spearman correlation coefficient (Conover 1980).

\section{Data reproducibility}

Observations were made on multiple trees/monitoring squares since 2007. When more than single tree/monitoring square observations were available, the within-site observations for the same phenophase were averaged to compare between the dates of single and mean observations. First, the onset dates were compared between the dates of single and mean observations. The differences between the dates were calculated and classified according to the phenological stage. Second, the rates of change in the phenological time-series were estimated, separately for the series based on single and mean observations, using the Sen's (1968) slope. Potential changes in the rate of change (days decade ${ }^{-1}$ ) as well as in the statistical significance of the trends, based on the MK-statistic (Kendall, 1970; Mann, 1945), were compared for information on data reproducibility.

\section{Results}

\section{Characterising the dataset}

\section{Spatiotemporal distribution}

Over the first 10 years of the study period, the number of phenological observations was approximately one thousand per year. Since that date, the change in the monitoring protocol markedly increased the total number of observations (Fig. 2a). That is, there was an increase in the number of trees and monitoring squares (in the
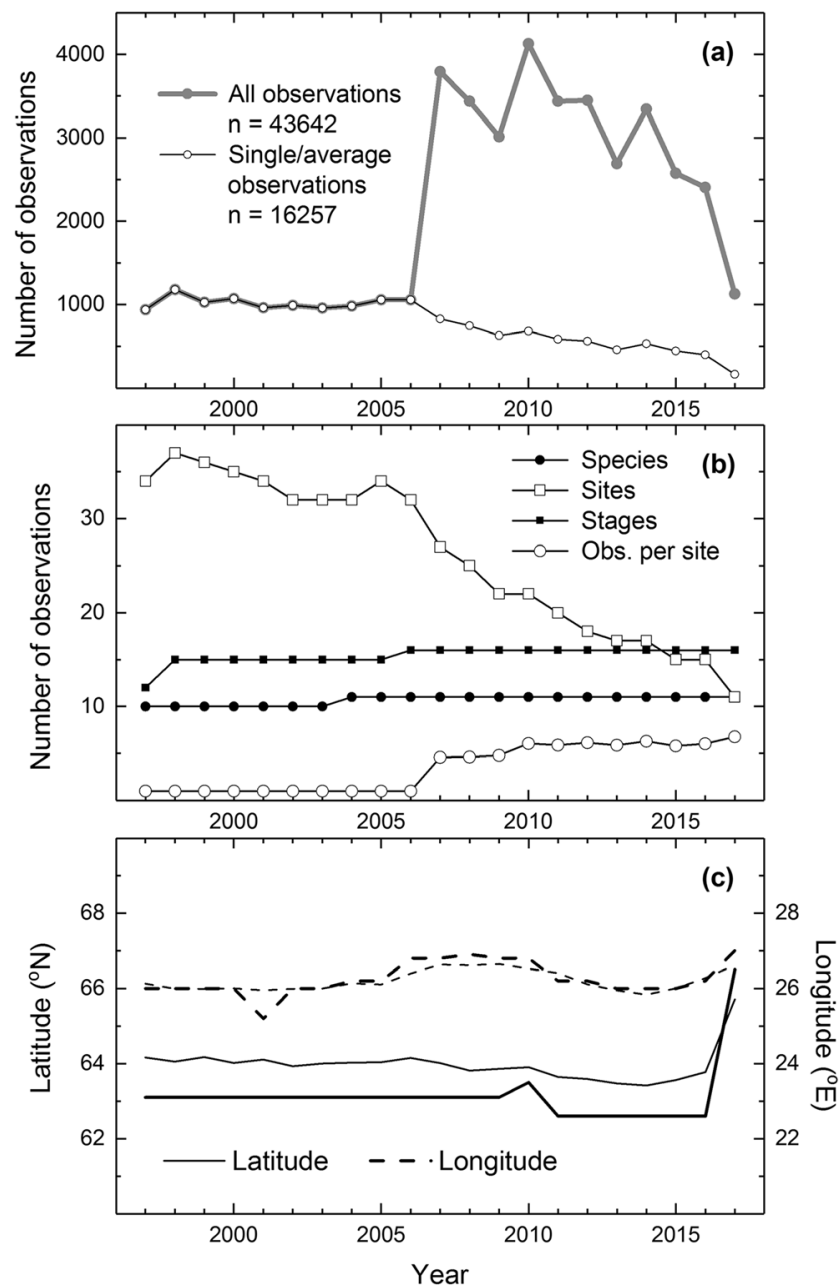

Fig. 2 Temporal variations in the numbers of plant phenological observations given as the number of all observations and those on single or averaged data from each site (a), and as the numbers of observed species, sites and phenological stages, the (mean) number of replications per site (b), and mean (grey lines) and median (black lines) latitudes and longitudes for $n=16,257$ observations (c)

case of shrubs) observed per site, i.e. in the number of within-site observations since 2007 (Fig. 2b).

Averaging the within-site observations for the same phenophase allows for a more reasonable comparison between the early (1997-2006) and late (2007-2017) observation periods. This averaging of dates (rounded to the closest integer) reduces the number of available data points to $n=$ 16,257 observations (this data is used hereafter for characterising the dataset, except for comparisons between single and mean dates). The number of mean observations (black line with open circles in Fig. 2a) shows that there was a steady decline in the number of observations over the late period. This decline is explained by the reducing number of observation sites over the same period (Fig. 2b). Comparison between the years 1998 and 2017 exemplifies the change in the spatial distribution of the sites for years with the highest (Fig. 1b) and lowest (Fig. 1c) number of sites. This shows that 
there are increasing gaps especially in the west-central Finland and northwest Finland (western Finnish Lapland) towards the end of the study period. By contrast, the numbers of observed plant species and phenological stages remained more or less constant (Fig. 2b). Since 2004, the observations were made on grey alder, an arboreal species of which phenology was not observed in this network before that date.

The coordinates of the 42 sites averaged $64.5^{\circ} \mathrm{N}$ and $25.6^{\circ}$ E. Time-dependent summary statistics for $n=16,257$ observations showed no marked fluctuations, an exception for the (last) year 2017 during which the observations represented latitudes around $66^{\circ} \mathrm{N}$ (Fig. 2c). Overall, this long-term stability would suggest that the geographical distribution of the observation sites was not subject to latitudinal or longitudinal shifts that would represent any large deviations from the central tendency.

\section{Phenophases and time-series}

The five most commonly observed species were Scots pine, downy birch, rowan, silver birch, and Norway spruce. Their observations accounted for $64.9 \%$ of the total amount, whereas the most commonly observed types of phenological stages were associated with the flowering, male flowering, berries ripe, leaves full-sized, and leaf colouring, and these observations accounting for $49.7 \%$ of the total amount.

There were altogether 40 combinations of species and their phenological stages, i.e. phenophases. The five most commonly observed phenophases were the budburst of downy birch, the flowering of bilberry, the downy birch leaves full-sized, the onset of height growth of Scots pine, and the bilberry berries unripe. These observations accounted for $16.0 \%$ of the total amount. Fifty percent and $90 \%$ of the observations were covered by 17 ad 33 most commonly observed phenophases.

There were altogether $n=1524$ phenological records representing the species, phenological stage, and site. As many as 66 of these records contained 21 observations, that is, they cover the full study period (1997-2017). The most frequent of them is the bud burst of downy birch, observed continuously over the 21-year study period at eight sites (Fig. 3). Moreover, there are four other 21-year time-series observed at least at five sites: the downy birch leaves fullsized, the leaf colouring of downy birch, the bud burst of silver birch, and the flowering of bilberry. In addition to these 21year time-series, there are one data point missing from 122 time-series, 85 time-series with two data points missing, and 83 time-series with three missing data points.

More than half of the phenological records $(n=808)$ contained at least 10 observations. These time-series contain a total number of $n=12,862$ observations representing 39 phenophases. This dataset was used for detecting the temporal trends in the phenological time-series in the following sections, if not otherwise indicated.

\section{Temporal trends}

\section{Assessment of temporal trends}

The $n=808$ phenological records with at least 10 years of data were used for trend analyses. The minimum length of 10 years of data was chosen to perform the analyses of trends (Table S1) for a sizeable amount of the records. Sixty-two percent $(n=500)$ of the time-series exhibited negative trends (Sen's slope), of which $20 \%(n=99)$ were statistically significant $(p<0.05)$. At the same time, $30 \%(n=244)$ of the timeseries showed positive trends, of which $14 \%(n=35)$ were statistically significant $(p<0.05)$. Eight percent $(n=64)$ of the time-series showed zero slope.

Furthermore, the slopes were grouped according to the phenophase (Fig. 4). Such an examination revealed that the temporal trends were excessively negative for spring (AprilMay) and early-summer (June) phenology, a result signalling earlier onset of the growing season. The trend slopes for these (April-June) phenophases were negative in 23 out of 24 cases, their median value indicating an overall change of 3.4 days decade ${ }^{-1}$. Positive trends were observed for a limited number of summer (July-August) and autumn (September) phenophases which would provide an indication of delayed phenology in six out of 15 cases. However, the median value for these slopes (for phenophases occurring in July through October) remained negative with an indication of an overall change of 0.6 days decade ${ }^{-1}$. That is, the phenological indications of the later part of the growing season were clearly more variable with markedly less consistent than those observed for spring and early-summer phenology.

\section{Geographical variation in trends}

Comparisons of the trend strengths and sites' coordinates indicated that there might be some weak latitude- and longitudedependent variations. Negative and statistically significant $(p<0.001)$ correlation was found between the slope estimates and sites' latitudes for spring and early-summer phenophases (Table 1), indicating relatively stronger signals of advancing spring and early-summer phenology towards the northern part of the country. Moreover, negative and statistically significant $(p<0.05)$ correlation was also obtained between the slope estimates and sites' longitudes for spring and early-summer phenology, implying somewhat a stronger signal of advancing spring towards the eastern part of the country. For summer/ autumn phenophases, by contrast, the trend slope estimates and sites' longitudes were positively and statistically significantly $(p<0.05)$ correlated, indicating progressively later summer/autumn phenology towards the eastern part of the country. That the mean location of the observations sites did not illustrate considerable shifts through time (Fig. 2c) 
Fig. 3 Phenological time-series of the bud burst of downy birch observed at eight sites, representing the latitudes between $70^{\circ} \mathrm{N}$ and $60^{\circ} \mathrm{N}$, through the 21 year period (1997-2017) (for site names, see Fig. 1a)

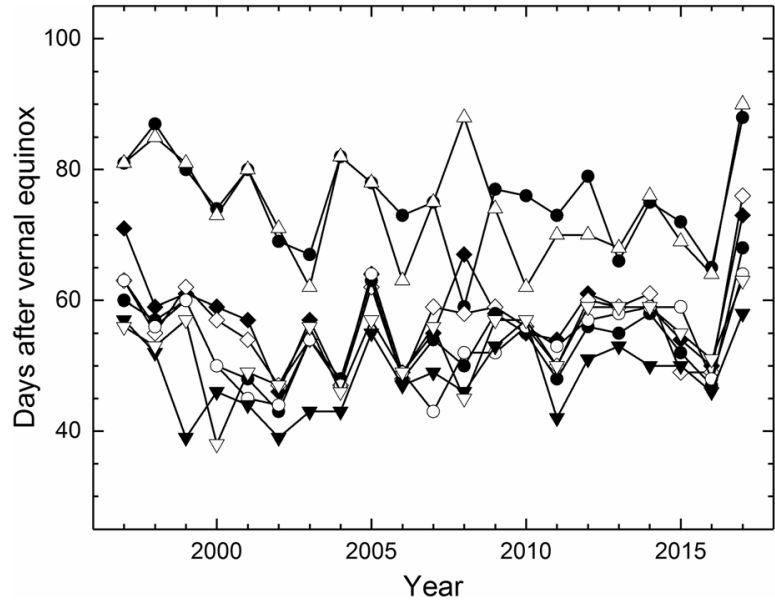

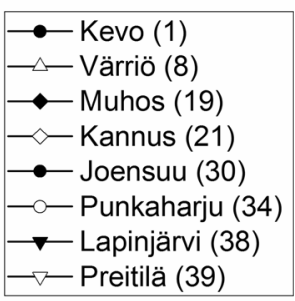

suggests no corresponding biases in geographical variations in the trends as observed here.

\section{Single and mean dates}

Altogether, $n=5699$ observations were based on more than single tree/monitoring square, making it possible to compare between the dates of single and mean observations. The majority of these observations $(62.8 \%)$ were identical, that is, the dates based on single tree/monitoring square (remaining the same through the study period) were exactly the same as those based on observations on multiple trees/monitoring squares. An additional one-third $(32.1 \%)$ of observations had a difference less than 5 days. The remaining observations with larger
Fig. 4 Trends in time-series of phenological observations over the 21-year period (1997-2017). Vertical axis indicates the median of the slopes estimated for each of the phenophases. Horizontal dashed lines represent the median levels of the spring and earlysummer (April-June) and summer/autumn (July-October) phenophases. For actual values, see Table S1

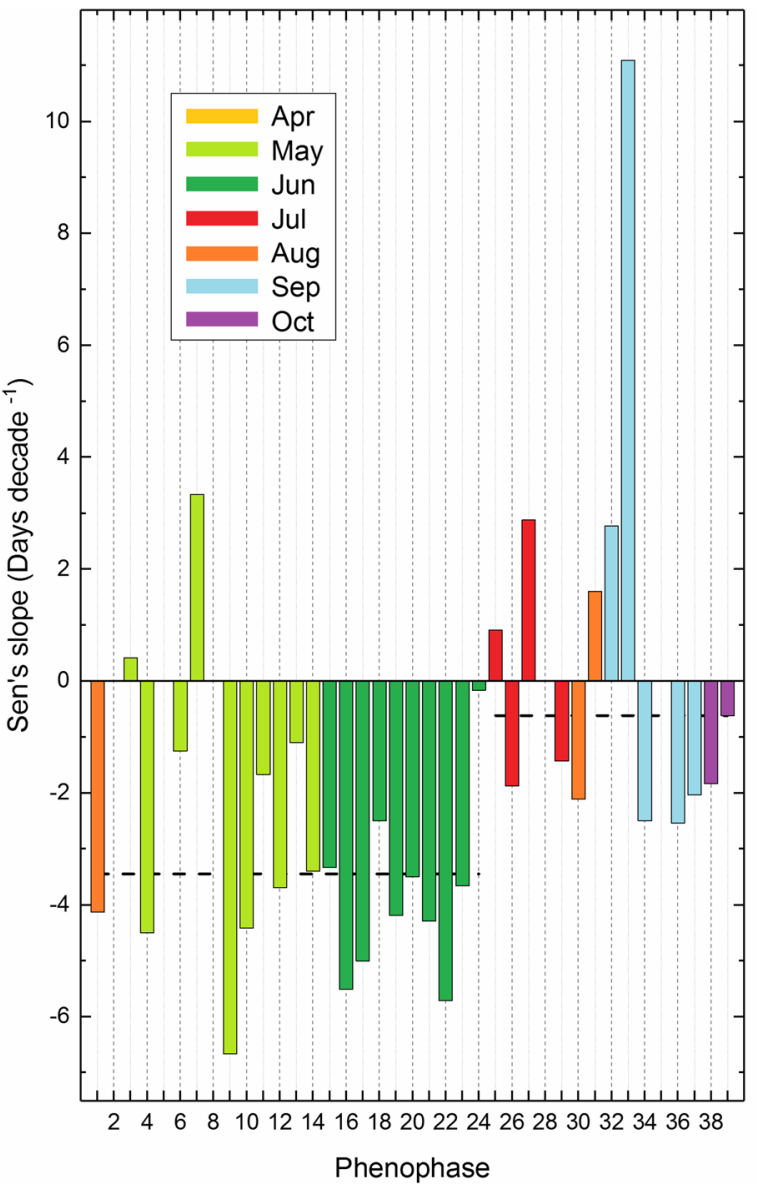

(1) Unset of male tlowerıng grey alder (2) Onset of male flowering_silver birch

(3) Bud scales opened_rowan

(4) Onset of height growth_Scots pine

(5) Bud burst_silver birch

(6) Bud burst downy birch

(7) Onset of male flowering_downy birch

(8) Leaves opened_rowan

(9) Onset of height growth_Norway spruce

(10) Flowering_bilberry

(11) Onset of female flowering_Norway spruce

(12) Flowering_bird-cherry

(13) Onset of male flowering_Norway spruce

(14) Female flowering $100 \%$ Norway spruce

(15) Leaves full-sized_silver birch

(16) Onset of female flowering_Scots pine

(17) Onset of male flowering_Scots pine

(18) Leaves full-sized_downy birch

(19) Onset of male flowering_common juniper

(20) Leaves full-sized_aspen

(21) Flowering_rowan

(22) Female flowering 100\%_Scots pine

(23) Flowering_cowberry

(24) Berries unripe_bilberry

(25) End of height growth_Scots pine

(26) End of height growth_Norway spruce

(27) Berries unripe_cowberry

(28) Shedding of seeds_downy birch

(29) Berries ripe_bilberry

(30) Berries ripe_bird-cherry

(31) Berries ripe_rowan

(32) Berries ripe_cowberry

(33) Leaf colouring rowan

(34) Leaf colouring_downy birch

(35) Leaf colouring_aspen

(36) Leaf colouring_silver birch

(37) Leaf fall_downy birch

(38) Leaf fall_aspen

(39) Leaf fall_silver birch 
Table 1 Correlations between the trend slopes for the phenological time-series and their sites' latitudes and longitudes, and the number of phenological time-series ( $n$ ) having at least ten data points over the 21year period (1997-2017). Calculations were done for the groups of phenological data representing spring/early-summer (April-June; AMJ) and summer/autumn (July-October; JASO) trends (see Fig. 4). Statistical significance at levels $p<0.05, p<0.01$, and $p<0.001$ are denoted by one $(*)$, two $(* *)$, and three $(* * *)$ asterisks, respectively

\begin{tabular}{lcrc}
\hline & Latitude & Longitude & $n$ \\
\hline AMJ & $-0.284^{* * *}$ & $-0.100^{*}$ & 513 \\
JASO & 0.043 & $0.119^{*}$ & 295 \\
\hline
\end{tabular}

within-site difference were clearly dominated by autumn phenology (Fig. 5a, b). Phenological stages such as leaf colouring and leaf fall together accounted for approximately half (53.7\%) and two-thirds (65.9\%) of the dates with at least 5 and 10 days difference, respectively.

Focussing on the phenological time-series based one tree/ monitoring square reduced the amount of phenological data to $n=798$ time-series (with at least ten data points over the 21year period). Comparison between the trends assessed for the two types of time-series showed no large deviations (Fig. 5c). Nearly half of the time-series (47.5\%) showed a difference in temporal trends of less than 0.1 days decade ${ }^{-1}$, judged from their trend estimates, and more than three quarters of them $(77.1 \%)$ less than 1 day decade ${ }^{-1}$. Again, most of the changes in the significance levels of the trends were observed for leaf colouring and leaf fall. Nine out of sixteen time-series of leaf colouring and leaf fall were non-significant for the time-series based on mean dates but significant $(p<0.05)$ for dates based on one tree/monitoring square. Clearly, the results suggest that multitude of observations would warrant more unbiased estimates for these observations of autumn phenology (i.e. leaf colouring and leaf fall).

\section{Discussion}

\section{Spring signals}

We observed a clear signal of advancing spring and earlysummer phenology over the 1997-2017 period. These indications concur with several previous phenological findings on national and European level. An average advance of spring/ summer 2.5 days decade $^{-1}$ in Europe between the years 1971 and 2000 (Menzel et al. 2006) was more recently exceeded by estimations of flowering onsets advancing $2.2-$ 9.6 days decade ${ }^{-1}$ as specifically obtained for boreal conditions over an extended period (1971-2010) (Templ et al. 2017). Calculated from data deposited in the PEP725 database, where the observations north of $60^{\circ} \mathrm{N}$ are excessively
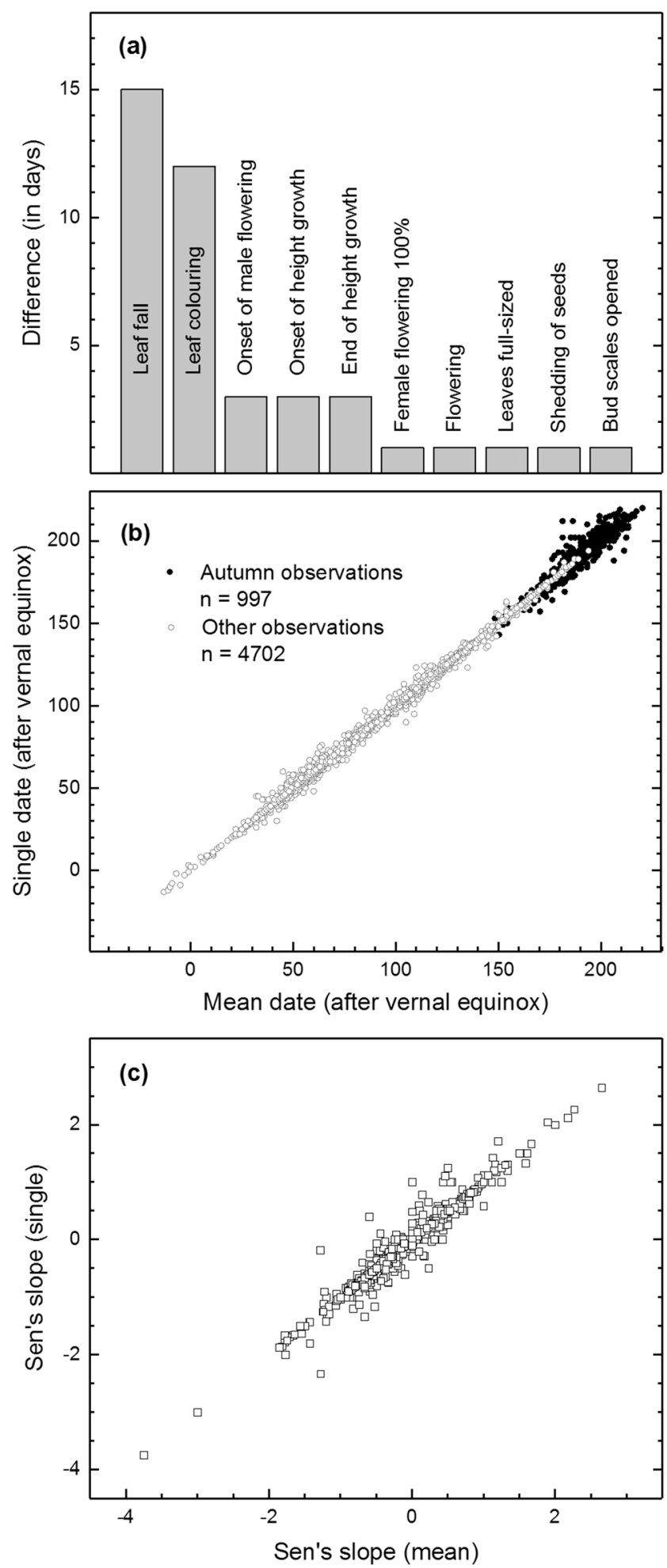

Fig. 5 Comparison between the single and mean observations per site. Phenological stages with sizeable difference ( $\geq 10$ days) between the dates of single and mean observations (a). Comparison between the autumn (leaf fall and leaf colouring) and other observations based on single and mean dates (b). Comparison of the $n=798$ Sen's slope (days year ${ }^{-1}$ ) estimates obtained for the phenological time-series based on single and mean observations over the 21-year period (1997-2017) (c) 
of Finnish origin (see Templ et al. 2018), i.e. the FNPN dataset, the latter trend estimates ought to agree particularly with our results. The average advance of spring/early-summer phenology obtained in this study as 3.4 days decade ${ }^{-1}$ (Fig. 4) is rather compatible with both of the foregoing European-scale estimates, more so with those of Templ et al. (2017), this agreeing also with their remark that more pronounced phenological changes are to be found in the boreal conditions, i.e. northern Europe and over the recent years.

Comparisons with previous FNPN studies, however, show that the average advance of spring/early-summer phenology did not quite reach those derived specifically for the spring phenophases in northern part of the country (1020 days decade $^{-1}$ ) (Pudas et al. 2008b) or for the bud burst of Betula pubescens through the country during the 19972006 period (7-14 days decade ${ }^{-1}$ ) (Pudas et al. 2008a). More recently, however, the timing of bud burst of $B$. pubescens was found to advance by 5 days decade ${ }^{-1}$ in the northern boreal zone (i.e. northern Finland) but to remain constant in the southern and middle boreal zones in Finland; these estimations employing the FNPN data from 1997 to 2013 (Poikolainen et al. 2016). These differences could be explained by at least two possible factors. First, the shorter period of investigation (Pudas et al. 2008a, b) may have resulted in steeper slopes estimates. This reasoning would resonate with that of Poikolainen et al. (2016) who noticed the potential biases in estimating trend for short phenological time-series. Second, the stronger trends in the northern part of the country (Pudas et al. 2008b) may be simply explained by our results showing a latitudinal correlation indicative of more prominent signals of advancing spring and earlysummer phenology towards the north (Table 1).

More generally, the signals of spring advance have been reported in Finnish phenological studies for trees, shrubs, grasses, agricultural plants, migratory birds, and insects (Lappalainen et al. 2008; Linkosalo et al. 2009; Holopainen et al. 2013) as well as for lake and river ice breakups (Helama et al. 2013; Korhonen 2019; Norrgård and Helama 2019). Obtained from data representative of plant and animal kingdoms, biotic and abiotic phenomena and over various time intervals, these studies add to the accumulating evidence suggesting various types of natural systems being largely driven by a common climatic forcing. Long-term warming of spring temperatures has in fact been shown to have continued in Finland over the past 100-150 years (Tuomenvirta 2004; Tietäväinen et al. 2010), this trend of warming remaining verified also by palaeoclimatic evidence (Holopainen et al. 2009).

\section{Autumn signals}

The autumn signal was, in general, much less consistent than that observed for the advancing spring. First, the proportion of positive trends increased towards the later part of the growing season whereas the overall level of the trend slopes remained slightly negative for phenophases occurring in July through October (see Fig. 4). Second, the autumn phenology (pertaining at least to leaf colouring and leaf fall) was more variable within each site which inevitably results in some loss of accuracy (Fig. 5a, b). Even so, the phenology based on mean dates did correspond with that based on single observations, which lent support to initial indications also of autumn phenology. Even so, it remains obvious that observations of at least leaf colouring and leaf fall show more within-site variations than the other phenological stages (Fig. 5a) and that multitude of observations per site would warrant more widely reliable estimates of these autumnal stages.

That the spring and early-summer phenology is advancing and some of the phenophases occurring in summer/autumn delaying could potentially indicate that the growing season is lengthening. Interestingly, this would also agree with calculations and projections showing prolongations of thermal growing season in the same region over the past and future decades (Linderholm et al. 2008; Ruosteenoja et al. 2011). It is notable, however, that the FNPN data shows also a number of observations indicative of progressively earlier summer/ autumn phenology (see Fig. 4). This inconsistency demonstrates that there is perhaps no assured way to reasonably interpret the finer details of this potential change from our results. Likely, it can be interpreted as being due to noise whose intensity exceeds that present in spring and earlysummer phenology. This line of reasoning would generally follow the results showing more ambiguous trends for the autumn phenology, in comparison with spring phenology, at least in boreal conditions (Pudas et al. 2008a, b; Poikolainen et al. 2016). Intriguingly, the leaf colouring of birch in northern Finland, included in a previous climatic analysis of Holopainen et al. (2013), was found to be best explained by spring (May) rather than autumn temperatures, albeit it could be emphasised that temperature correlations with this phenological stage were generally low. Results with similar implications were reported from a European-scale study finding no clear relationship between trends of temperature and leaf colouring/leaf fall (Menzel et al. 2006). These findings would not be at odds with recent indications suggesting that autumn phenology can be predicted using spring phenology (Keenan and Richardson 2015).

\section{The FNPN/Finnish phenological data}

The FNPN dataset is not the only assemblage of phenological data in Finland. Historically, the importance of collecting phenological data was advocated by Carl von Linné who also initiated the station network (Dahl and Langvall 2008). Soon after, however, as pointed out by Holopainen et al. (2018), Linné's recommendation to create phenological datasets was 
remembered only in Finland where the efforts have indeed continued by several generations of volunteers, with varying levels of institutional enthusiasm to organise the activity, since 1750s. Indeed, several institutional organisations and scientific societies have been involved in this long-lasting process, the history of which itself has been reviewed in previous publications (Kubin et al. 2008; Terhivuo et al. 2009; Holopainen et al. 2012). A large body of this work until the 1870s was compiled and published already by Moberg $(1857,1860$, $1885,1894)$ from whose works the plant data has been recently digitised (Holopainen et al. 2018), the more recent parts of the subsets of the corresponding data being digitised and analysed mainly for purposes of the climatic analysis (Lappalainen and Heikinheimo 1992; Häkkinen et al. 1995; Holopainen et al. 2006, 2013; Linkosalo et al. 2009). Compared with these data, the FNPN dataset may form the most consistent and homogenous collection of observations. In the context of European phenological data, it could be classified among the national specialist networks (Menzel et al. 2006), in comparison with the volunteering activities.

The FNPN dataset consists of observations made on eleven tree and shrubs species and fifteen phenological stages. These data constitute forty different variables of corresponding phenophases collected using a unified protocol (Kubin et al. $2007 \mathrm{a}, \mathrm{b}$ ) at 42 sites between $70^{\circ} \mathrm{N}$ and $60^{\circ} \mathrm{N}$. As such, the FNPN data provides a strong high-latitude contribution to the European Phenological database PEP725 (Koch et al. 2008; Templ et al. 2018) over the 21-year period of available observations. That is, the recently published version of the PEP725 database (Templ et al. 2018) contains almost no sites north of $60^{\circ} \mathrm{N}$ other than FNPN observations and is entirely based on FNPN data north of around $65^{\circ} \mathrm{N}$. Yet, the boreal phenology was recently shown to exhibit significant advancements in plant flowering onset dates with magnitudes exceeding the less pronounced changes in other biogeographical regions (continental, alpine, Pannonian, and Mediterranean) (Templ et al. 2017); these results demonstrating the importance of understanding the high-latitude phenological responses to climatic changes.

This study provides a characterisation of this northern dataset with outlines of assessing the trends in the FNPNbased phenological time-series over the 1997-2017 period. Even so, the spring and summer seasons of 2018 were marked by unusually hot weather across northern and central Europe and, according to Albergel et al. (2019), the summer 2018 was warmest in Europe since continental records began in 1910. In Finland, May and July 2018 were exceptionally warm, the July temperature anomalies reaching their extremes in northern Finland (Sinclair et al. 2019). Moreover, Vogel et al. (2019) attributed the heat extremes experienced during the same summer across the northern hemisphere to humaninduced climate change and Albergel et al. (2019) showed the impacts of this heatwave on leaf area index of which negative anomalies exceeded two standard deviations from the mean in north-western Europe both for June through October season and for July. Cessation of phenological observations in 2017 due to decline in financial support precludes any investigations of the potential effects from this anomalous heat on phenology in the context of the FNPN dataset. Ironically, the situation demonstrates the continuous need for data collection to provide evidence relating to advancing climatic changes and anomalies.

Acknowledgements The anonymous referees are thanked for giving valuable suggestions for improving this article. Open access funding provided by Natural Resources Institute Finland (LUKE).

Funding information This work was supported financially by the Academy of Finland and several projects at the Finnish Forest Research Institute and later at the Natural Resources Institute Finland. The manuscript was written while the first author was supported by Grant 288267 from the Academy of Finland. One of the authors, Eero Kubin, is as a founder and organiser of the Finnish National Phenological Network.

\section{Compliance with ethical standards}

Conflict of interest The authors declare that they have no conflict of interest.

Open Access This article is licensed under a Creative Commons Attribution 4.0 International License, which permits use, sharing, adaptation, distribution and reproduction in any medium or format, as long as you give appropriate credit to the original author(s) and the source, provide a link to the Creative Commons licence, and indicate if changes were made. The images or other third party material in this article are included in the article's Creative Commons licence, unless indicated otherwise in a credit line to the material. If material is not included in the article's Creative Commons licence and your intended use is not permitted by statutory regulation or exceeds the permitted use, you will need to obtain permission directly from the copyright holder. To view a copy of this licence, visit http://creativecommons.org/licenses/by/4.0/.

\section{References}

Albergel C, Dutra E, Bonan B, Zheng Y, Munier S, Balsamo G, de Rosnay P, Munoz-Sabater J, Calvet J (2019) Monitoring and forecasting the impact of the 2018 summer heatwave on vegetation. Remote Sens 11. https://doi.org/10.3390/rs11050520

Conover WJ (1980) Practical nonparametric statistics, 2nd edn. Wiley, New York

Dahl Å, Langvall O (2008) Observations on phenology in Sweden past and present. In: Nekovár J (ed) The history and current status of plant phenology in Europe. COST Action 725, Vammala, pp 161165

Eastman J, Sangermano F, Machado E, Rogan J, Anyamba A (2013) Global trends in seasonality of normalized difference vegetation index (NDVI), 1982-2011. Remote Sens 5:4799-4818

Häkkinen R, Linkosalo T, Hari P (1995) Methods for combining phenological time series: application to bud burst in birch (Betula pendula) in Central Finland for the period 1896-1955. Tree Physiol 15:721726 
Hamunyela E, Verbesselt J, Roerink G, Herold M (2013) Trends in spring phenology of western European deciduous forests. Remote Sens 5: 6159-6179

Helama S, Jiang J, Korhonen J, Holopainen J, Timonen M (2013) Quantifying temporal changes in Tornionjoki river ice breakup dates and spring temperatures in Lapland since 1802. J Geogr Sci 23: 1069-1079

Holopainen J, Helama S, Timonen M (2006) Plant phenological data and tree-rings as palaeoclimate indicators since AD 1750 in SW Finland. Int J Biometeorol 51:61-72

Holopainen J, Helama S, Kajander JM, Korhonen J, Launiainen J, Nevanlinna H, Reissell A, Salonen V-P (2009) A multiproxy reconstruction of spring temperatures in south-west Finland since 1750. Clim Chang 92:213-233

Holopainen J, Gregow H, Helama S, Kubin E, Lummaa V, Terhivuo J (2012) History of Finnish plant phenological observations since the 1750s. Sorbifolia 43:51-66

Holopainen J, Helama S, Lappalainen H, Gregow H (2013) Plant phenological records in northern Finland since the 18th century as retrieved from databases, archives and diaries for biometeorological research. Int J Biometeorol 57:423-435

Holopainen J, Helama S, Väre H (2018) Digitizing the plant phenological dataset (1750-1875) from collections of Professor Adolf Moberg: Towards the development of historical climate records. Agric For Meteorol 253-254:141-150

Keenan TF, Richardson AD (2015) The timing of autumn senescence is affected by the timing of spring phenology: implications for predictive models. Glob Chang Biol 21:2634-2641

Kendall MG (1970) Rank Correlation Methods, 4th ed. Griffin, London

Koch E, Adler S, Lipa W, Ungersböck M, Zach-Hermann S (2008) The Pan European Phenological database PEP725. In: Matzarakis A, Mayer H, Chmielewski F-M (eds) Proceedings of the 7 th Conference on Biometeorology, Berichte des Meteorologischen Instituts der Albert-Ludwigs-Universität Freiburg, vol 20. AlbertLudwigs-University of Freiburg, Germany, pp 331-335

Korhonen J (2019) Long-term changes and variability of the winter and spring season hydrological regime in Finland. Doctoral dissertation. Report Series in Geophysics 79. University of Helsinki

Kubin E (1993) Metsäekologisen havaintoverkoston kehittäminen. Abstract: improvement of forest ecological monitoring network. The Finnish Forest Research Institute Research Papers 461:1-26

Kubin E, Kotilainen E, Terhivuo J, Venäläinen A (2006) Phenological observations in Finland. Memoranda Soc Fauna Flora Fenn 82:3344

Kubin E, Kotilainen E, Poikolainen J, Hokkanen T, Nevalainen S, Pouttu A, Karhu A, Pasanen J (2007a) Fenologisen havaintoverson seurantaohjeet. Finnish Forest Research Institute, Muhos Research unit

Kubin E, Kotilainen E, Poikolainen J, Hokkanen T, Nevalainen S, Pouttu A, Karhu A, Pasanen J (2007b) Monitoring instructions of the Finnish national phenological network. Finnish Forest Research Institute, Muhos Research unit

Kubin E, Pudas E, Venäläinen A, Terhivuo J (2008) Phenological recording in Finland. In: Nekovár J (ed) The history and current status of plant phenology in Europe. COST Action 725, Vammala, pp 68-75

Lappalainen H, Heikinheimo M (1992) Relations between climatological and plant phenological observations. Survey of plant phenological observations in Finland from 1896 to 1965, vol 1. Meteorological Publications 20:1-74

Lappalainen HK, Linkosalo T, Venäläinen A (2008) Long-term trends in spring phenology in a boreal forest in central Finland. Boreal Environ Res 13:303-318

Linderholm HW, Walther A, Chen D (2008) Twentieth-century trends in the thermal growing season in the Greater Baltic Area. Clim Chang $87: 405-419$
Linkosalo T, Häkkinen R, Terhivuo J, Tuomenvirta H, Hari P (2009) The time series of flowering and leaf bud burst of boreal trees (18462005) support the direct temperature observations of climatic warming. Agric For Meteorol 149:453-461

Mann HB (1945) Nonparametric tests against trend. Econometrica 13: 245-259

Meier U (2001) Growth stages of mono and dicotyledonous plants. $\mathrm{BBCH}$ Monograph, Federal Biological Research Centre for Agriculture and Forestry, Bonn

Menzel A (2000) Trends in phenological phases in Europe between 1951 and 1996. Int J Biometeorol 44:76-81

Menzel A (2002) Phenology: its importance to the global change community. Clim Chang 54:379-385

Menzel A, Sparks T, Estrella N, Koch E, Aasa A, Ahas R, Alm-Kübler K, Bissolli P, Braslavska O, Briede A, Chmielewski FM, Crepinsek Z, Curnel Y, Dahl A, Defila C, Donnelly A, Filella Y, Jatczak K, Mage F, Mestre A, Nordli Ø, Penuelas J, Pirinen P, Remisova V, Scheifinger H, Striz M, Susnik A, van Vliet AJH, Wielgolaski FE, Zach S, Zust A (2006) European phenological response to climate change matches the warming pattern. Glob Chang Biol 12:19691976

Menzel A, Yuan Y, Matiu M, Sparks T, Scheifinger H, Gehrig R, Estrella $\mathrm{N}$ (2020) Climate change fingerprints in recent European plant phenology. Glob Chang Biol 26:2599-2612

Moberg A (1857) Naturhistoriska dag-anteckningar gjorda i Finland, Åren 1750-1845. Notiser ur Sällskapets pro Fauna \& Flora fennica förhandlingar Bihang till. Acta Soc Sci Fenn 3:95-250

Moberg A (1860) Klimatologiska iakttagelser i Finland, föranstaltade och utgifna af Finska Vetenskaps-Societen. Första delen. År 1846-1855. I. Bidrag till Finlands naturkännedom, etnografi och statistic 7:1361

Moberg A (1885) Klimatologiska iakttagelser i Finland, föranstaltade och utgifna af Finska Vetenskaps-Societen. Andra delen. År 1856-1875. I. Fenologiska anteckningar. Bidrag till kännedom af Finlands natur och folk 41:1-321

Moberg A (1894) Fenologiska iakttagelser i Finland åren 1750-1845. Utgifna af Finska Vetenskaps-Societeten. Finska LitteraturSällskapets tryckeri, Helsingfors. Bidrag till kännedom af Finlands Natur och Folk 55:1-165

Nekovář J, Koch E, Kubin E, Nejedlik P, Sparks T, Wielgolaski FE (2008) COST action 725 - the history and current status of plant phenology in Europe. COST Office, Brussels

Norrgård S, Helama S (2019) Historical trends in spring ice breakup for the Aura River in Southwest Finland, AD 1749-2018. Holocene 29: 953-963

Parmesan C, Yohe G (2003) A globally coherent fingerprint of climate change impacts across natural systems. Nature 421:37-42

Piao S, Liu Q, Chen A, Janssens IA, Fu Y, Dai J, Liu L, Lian X, Shen M, Zhu X (2019) Plant phenology and global climate change: current progresses and challenges. Glob Chang Biol 25:1922-1940

Poikolainen J, Karhu J, Kubin E (1997) Development of a plant phenological observation network in Finland. Finnish Forest Research Institute Research Papers 623:97-101

Poikolainen J, Tolvanen A, Karhu J, Kubin E (2016) Seventeen-year trends in spring and autumn phenophases of Betula pubescens in a boreal environment. Int J Biometeorol 60:1227-1236

Pudas E, Leppälä M, Tolvanen A, Poikolainen J, Venäläinen A, Kubin E (2008a) Trends in phenology of Betula pubescens across the boreal zone in Finland. Int J Biometeorol 52:251-259

Pudas E, Tolvanen A, Poikolainen J, Sukuvaara T, Kubin E (2008b) Timing of plant phenophases in Finnish Lapland in 1997-2006. Boreal Environ Res 13:31-43

Ranta E, Lindström J, Kaitala V, Crone E, Lundberg P, Hokkanen T, Kubin E (2010) Life history mediated responses to weather, phenology and large-scale population patterns. In: Hudson IL, Keatley MR (eds) Phenological research. Springer, pp 321-338 
Ruosteenoja K, Räisänen J, Pirinen P (2011) Projected changes in thermal seasons and the growing season in Finland. Int J Climatol 31:14731487

Sagarin R (2001) False estimates of the advance of spring. Nature 414: 600

Sagarin R (2009) Using nature's clock to measure phenology. Front Ecol Environ 7:296

Sagarin R, Micheli F (2001) Climate change in nontraditional data sets. Science 294:811

Schaber J, Badeck F-W (2005) Plant phenology in Germany over the 20th century. Reg Environ Chang 5:37-46

Sen PK (1968) Estimates of the regression coefficient based on Kendall's tau. J Am Stat Assoc 63:1379-1389

Sinclair VA, Mikkola J, Rantanen M, Räisänen J (2019) The summer 2018 heatwave in Finland. Weather 74:403-409

Templ B, Templ M, Filzmoser P, Lehoczky A, Bakšienè E, Fleck S, Gregow H, Hodzic S, Kalvane G, Kubin E, Palm V, Romanovskaja D, Vučetić V, Žust A, Czúcz B, NS-Pheno Team (2017) Phenological patterns of flowering across biogeographical regions of Europe. Int J Biometeorol 61:1347-1358

Templ B, Koch E, Bolmgren K, Ungersböck M, Paul A, Scheifinger H, Rutishauser T, Busto M, Chmielewski FM, Hájková L, Hodzić S, Kaspar F, Pietragalla B, Romero-Fresneda R, Tolvanen A, Vučetič V, Zimmermann K, Zust A (2018) Pan European Phenological database (PEP725): a single point of access for European data. Int J Biometeorol 62:1109-1113

Terhivuo J, Kubin E, Karhu J (2009) Phenological observations since the days of Linné in Finland. Ital J Agrometeorol 14:45-49

Tietäväinen H, Tuomenvirta H, Venäläinen A (2010) Annual and seasonal mean temperatures in Finland during the last 160 years based on gridded temperature data. Int J Climatol 30:2247-2256

Tuomenvirta H (2004) Reliable estimation of climatic variations in Finland. Finnish Meteorological Institute Contributions, 43. Doctoral dissertation. University of Helsinki

Vogel MM, Zscheischler J, Wartenburger R, Dee D, Seneviratne SI (2019) Concurrent 2018 hot extremes across Northern Hemisphere due to human-induced climate change. Earth's Future 7:692-703

Wielgolaski FE, Inouye DW (2013) Phenology at high latitudes. In: Schwartz MD (ed) Phenology: an integrative environmental science. Springer, Dordrecht, pp 225-247

Williams P, Alessa L, Abatzoglou JT, Kliskey A, Witmer F, Lee O, Trammel J, Beaujean G, Venema R (2018) Community-based observing networks and systems in the Arctic: human perceptions of environmental change and instrument-derived data. Reg Environ Chang 18:547-559

Zhou J, Cai W, Qin Y, Lai L, Guan T, Zhang X, Jiang L, Du H, Yang D, Cong Z, Zheng Y (2016) Alpine vegetation phenology dynamic over 16years and its covariation with climate in a semi-arid region of China. Sci Total Environ 572:119-128 